Article

\title{
Impact of Coastal Land Use Change on Shoreline Dynamics in Yunlin County, Taiwan ${ }^{\dagger}$
}

\author{
Kwong Fai A. Lo * and Chethika W. D. Gunasiri \\ Graduate Institute of Earth Science, Chinese Culture University, Taipei 11114, Taiwan; \\ E-Mail: chethikagunasiri@gmail.com
}

$\dagger$ Oral presentation in The Global Land Project (GLP) Asia Conference 2014, Session S0101: Assessment land Use Dynamics World Wide, Taipei, Taiwan, 24-26 September 2014.

* Author to whom correspondence should be addressed; E-Mail: andrewlo@faculty.pccu.edu.tw; Tel.: +886-2-2861-7201.

Received: 23 July 2014; in revised form: 30 September 2014 / Accepted: 30 September 2014 / Published: 13 October 2014

\begin{abstract}
Located in the west coast of Taiwan, Yunlin County is considered as one of the most industrialized counties. The impact of land use on the coastal zone is significantly high. The main objective of this study is to analyze the impact of coastal land use changes in Yunlin County between 1996 and 2011 on shoreline dynamics. Two sets of satellite images (SPOT and FORMOSAT-2) are used as major data sources, and all analyses are performed using Geographic Information Systems (GIS) techniques. Land use classification includes seven types. Their area changes and correlations with shoreline area changes are calculated. Results indicate that between 1996 and 2011, the Yunlin coastal zone has experienced substantial land use changes, with dramatic increase of industrial and residential area along with significant loss of sandy coast. For the last sixteen years, Yunlin shoreline has undergone both erosion and accretion position changes. However, accretion is more prominent and common in many places. The net shoreline change observed is an accretion area of $1.65 \mathrm{~km}^{2}$. Results also further reveal that area changes of agriculture, residential, abandoned and aquaculture lands have caused a negative impact on the shoreline, moving it landward. However, area changes of industrial land and the sandy coast have exerted a positive impact (shifting the shoreline towards the sea). This positive impact is mainly due to land reclamation projects and destruction of natural coasts. As such, this is not favorable for natural coastal environments. This study also clearly indicates that, human induced coastal land use changes do exist in Yunlin. These changes
\end{abstract}


may have created long-term shoreline position shifts and significant impact on its coastal environment.

Keywords: human impact; GIS; coastal land uses; industrialization; shoreline change

\section{Introduction}

Coastal regions are highly important, as they are the most intensely used areas settled by humans. They have been under intensive pressure throughout history and the situation is likely to continue in the future. Coastal areas are also favorable for development activities, as they are driven by many economic rationales such as, presence of natural resources (fisheries, mangroves and coral reefs), accessibility of residential, industrial and other development activities and having aesthetic value such as beaches and ocean views. As a result of this, changes of land use patterns are one of the most significant environmental issues in many coastal areas all over the world.

The shoreline is the dry-wet boundary of the coast which is the line where the body of water and shore meets [1]. Because of the dynamic nature of the water body and the coastal land, the shoreline changes all the time and are never stable with either short-term or long-term positions. Short-term variations of shoreline positions are primarily seasonal and periodical, whereas long-term variations are generally due to sea level fluctuations or changes in the coastal sedimentary budget [2,3]. Changes of coastal land use patterns can directly impact changes in shoreline positioning [4,5]. The shoreline can be changed due to erosion and accretion [6], and as the nearby land use patterns change, erosion or accretion takes place resulting in changes of the shoreline. Changing shoreline position influences immediate coastal environments either positively or negatively $[7,8]$.

Taiwan is an island with an extensive coastline. The coastal area has exerted great socio-economic impact on this country. Taiwan's current population density is over 600 per $\mathrm{km}^{2}$, much higher than the average of the coastal zones worldwide which is only about 90 per $\mathrm{km}^{2}$ [9]. According to Lin [10], human involvements in coastal areas of Taiwan include mainly industrial and commercial activities which have resulted in shoreline modifications by numerous coastal engineering works. Many parts of the shoreline have changed greatly due to coastal erosion. This problem has become more significant over time. As Hsu et al. [11] indicates, about $80 \%$ of Taiwan's sandy shoreline has been suffering from erosion over the past few decades. Many studies reveal that the southwestern coast and the northeastern coast are more vulnerable [9]. Moreover, land use patterns of these coastal areas also have undergone significant changes.

Being one of the major industrialized counties in Taiwan, Yunlin County has experienced significant changes of land use patterns during the last few decades. These coastal land use changes may have direct impact on the neighboring shoreline. The objective of this study is, therefore, to study the impact of coastal land use changes on the shoreline along Yunlin County between 1996 and 2011. 


\section{Materials and Methods}

\subsection{Physical Setting of Yunlin Coastal Area}

Yunlin County is located in the west coastal region of Taiwan $\left(23^{\circ} 42^{\prime} 18^{\prime \prime} \mathrm{N}\right.$ and $\left.120^{\circ} 28^{\prime} 34^{\prime \prime} \mathrm{E}\right)$, in the southern part of the Chuoshui Stream alluvial fan, and between the new and old Huwei Stream. The widest east-west distance is about $50 \mathrm{~km}$ and the longest south-north distance is about $38 \mathrm{~km}$. The total area of the County is about $1291 \mathrm{~km}^{2}$. Ninety percent of the county is covered by plains, whereas $10 \%$ is in hilly terrain. The weather is of subtropical climate with average annual temperature of $22.6{ }^{\circ} \mathrm{C}$ and average annual rainfall of $1029 \mathrm{~mm}$. The coastal zone of the County covers four townships, Mailiao, Taisi, Sihhu, Kohu (Figure 1). In the last few decades, there have been large numbers of development activities taken place in the Yunlin coastal region.

Figure 1. Coastal townships of Yunlin County.

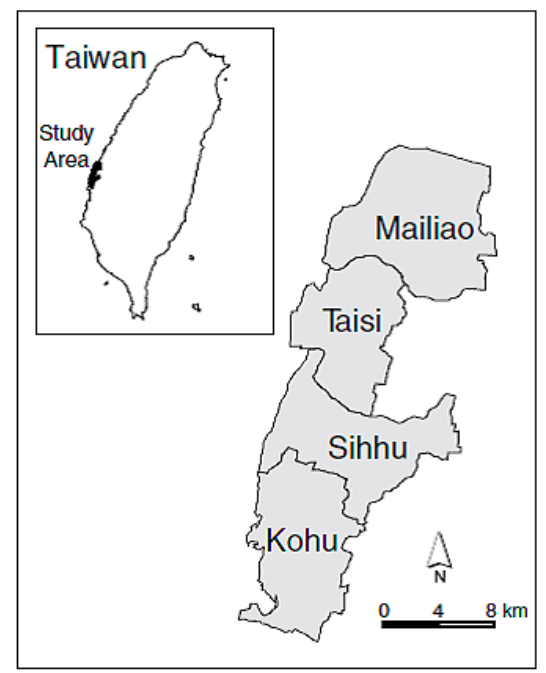

\subsection{Data Sources}

The analyses of land use and shoreline changes are performed using two sets of remote sensing satellite images: 1996 SPOT image (08/04/1996) and 2011 FORMOSAT-2 image (02/22/2011). The resolution of SPOT image is about $20 \mathrm{~m}$ and FORMOSAT-2 image is about $8 \mathrm{~m}$. Although the resolution of SPOT image, in general, is about $20 \mathrm{~m}$, the 1996 image obtained for this study is of high resolution quality. The resolution accuracy is about $10 \mathrm{~m}$, which is of comparable quality as the FORMOSAT-2 image. Both satellite images are already geo-referenced. However, they use different coordinate systems. Therefore, both are unified with a TW 97 Transverse Mercator coordinate system. A coastal belt, $5 \mathrm{~km}$ in width, along the entire Yunlin County, is selected as the study area to analyze the land use changes. This segment is segregated from both satellite images using ArcGIS 10.1.

\subsection{Preparation of Land Use Maps and Shoreline Mapping}

Visual interpretation is used to identify different land use types in the satellite images. The study area in both images is classified into seven different land use types: agriculture, aquaculture, industry, residential, sandy coast, vegetation and abandoned lands. Each land use type is delineated using 
on-screen digitization of ArcGIS 10.1. An area of approximately $5 \mathrm{~km}^{2}$ in the 1996 SPOT image is covered by clouds. The position of the shoreline is highly variable because of the dynamic nature of the coastal region. This study defines the shoreline as the dry-wet boundary of the coast, which approximates the high water level. The $\mathrm{X}$ and $\mathrm{Y}$ coordinates of the shorelines positions for both years are identified in $100 \mathrm{~m}$ intervals using ArcGIS 10.1, and are mapped in Microsoft Excel 2010 for both 1996 and 2011.

Since shoreline positions experience daily short-term changes as a result of tidal activity, it is extremely important to account for these changes when extracting shoreline positions in long-term shoreline analysis. For this study, tidal data of Yunlin shoreline for August 1996 and February 2011 are obtained from the Taiwan Central Weather Bureau tidal gauge located at $23^{\circ} 37^{\prime} 07^{\prime \prime} \mathrm{N}, 120^{\circ} 08^{\prime} 15^{\prime \prime} \mathrm{E}$. According to the tidal data, the 1996 SPOT image (August 4th at 2:48 am) was at a high tide level. Based on the shoreline definition used in this study, no adjustments are needed for calculating the position of shoreline. The 2011 FORMOSAT-2 satellite image (22 February between 11:30 am-12:00 pm) was also taken during high tide level of that day. Therefore, shorelines positions extracted from both satellite images can be directly used for analysis without further adjustments.

\subsection{Calculation of Area Change}

The area of each land use type in 1996 and 2011 land use maps is extracted by Geographic Information System (GIS) techniques. The area change occurred in each land use type is then calculated according to the following landscape dynamic model:

$$
\mathrm{K}=(\mathrm{Uo}-\mathrm{Ut}) / \mathrm{Uo} \times 100 \%
$$

where,

$\mathrm{K}=$ area change of each land use type

$\mathrm{Uo}=$ area of initial time

$\mathrm{Ut}=$ area of end time

The space between shoreline positions in 1996 and 2011 is digitized as polygons and the area of each polygon is then calculated. Comparing positions of two shorelines, whether the shoreline has undergone accretion or erosion is also evaluated. If erosion occurs, the area is assigned a negative (-) value, and in the case of accretion, a positive $(+)$ value is assigned. The sum of all positive and negative values gives the total shoreline area change between 1996 and 2011. If the 2011 shoreline has moved towards land compared to 1996, it is considered as negative impact to the shoreline and if it has shifted towards sea, it is regarded as a positive impact.

\subsection{Relationship of Shoreline and Land Use Changes}

The relationships between area changes of different land use types and the shoreline dynamics is conducted on the $5 \mathrm{~km}$ width coastal belt along the entire Yunlin County. To study the land area size influence on shoreline, the study area is divided into horizontal segments. The vertical (north-south) distance of segments is chosen to vary from $1 \mathrm{~km}$ to $5 \mathrm{~km}$. Since the width of study area is fixed (5 km from shoreline to land), the study area for both years is subdivided into horizontal segments with areas of $1 \times 5 \mathrm{~km}^{2}, 2 \times 5 \mathrm{~km}^{2}, 3 \times 5 \mathrm{~km}^{2}, 4 \times 5 \mathrm{~km}^{2}$ and $5 \times 5 \mathrm{~km}^{2}$. Area of each land use type within each 
horizontal segment is calculated. Area change occurred between 1996 and 2011 is then computed. The net shoreline area change is also calculated for every horizontal segment.

To obtain the relationship between area of different land use types and shoreline area changes, a Pearson Product Moment Correlation is carried out. The area changes of each land use type for a horizontal segment is correlated with corresponding shoreline area changes to determine whether a positive or a negative impact occurs on the Yunlin shoreline.

\section{Results and Discussions}

\subsection{Coastal Land Use Changes between 1996 and 2011}

The total area of study site in 1996 is $186.44 \mathrm{~km}^{2}$ and 2011 is $176.60 \mathrm{~km}^{2}$. In both years, the largest part of the study area is covered by agriculture, followed by aquaculture, industrial area, residential area, sandy coast, vegetation and abandoned areas (Figure 2 and Table 1). Between 1996 and 2011, the Yunlin coastal area has experienced significant land use changes, in which agriculture, industry, residential, vegetation and abandoned lands showed area expansion and decreasing aquaculture and sandy coast lands. Industrial land depicts a dramatic (131.87\%) increase in land area. This is followed by residential, vegetation, agriculture and abandoned land with an increase of $72.03 \%, 39.26 \%, 0.8 \%$ and $0.31 \%$, respectively (Table 1 ). The sandy coast occupies a very small area in the study site. However, it shows the most significant area loss with reduction of $92.51 \%$, due mainly to rapid industrial activities along the Yunlin shoreline.

Figure 2. Land use maps in 1996 and 2011.

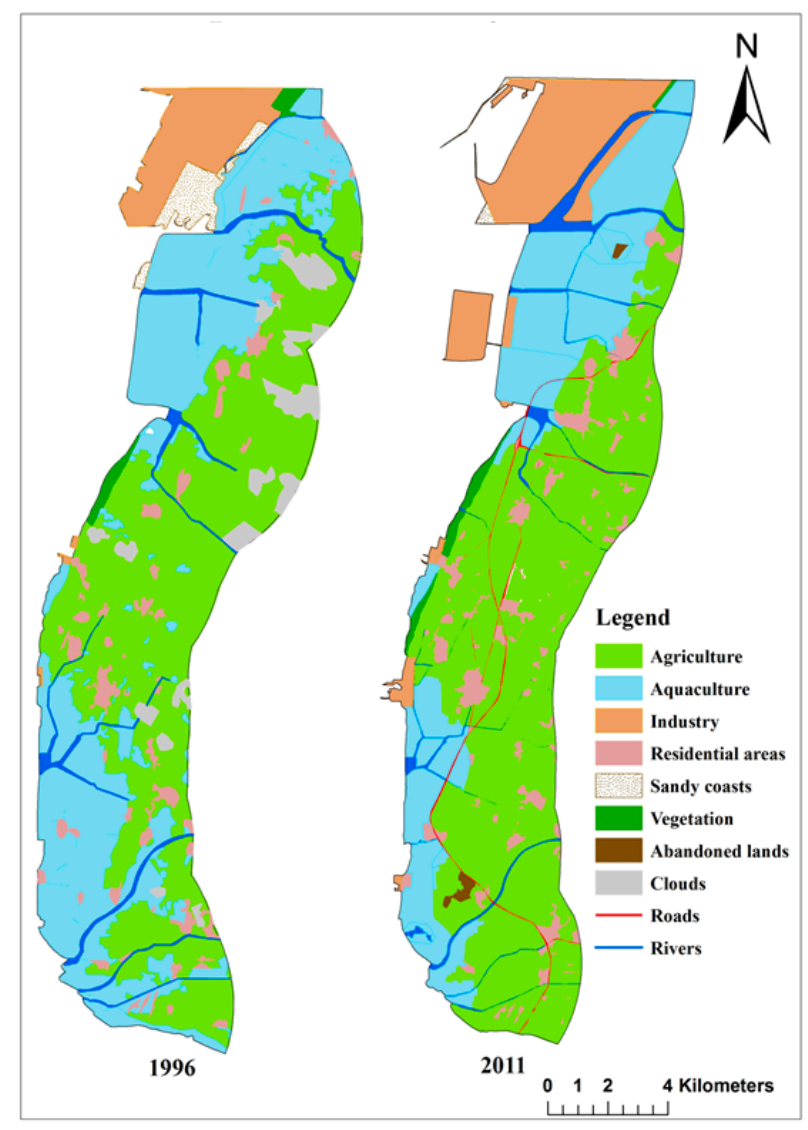


Table 1. Land use changes of Yunlin coastal zone between 1996 and 2011.

\begin{tabular}{lcccccc}
\hline \multirow{2}{*}{ Land use type } & \multicolumn{2}{c}{$\mathbf{1 9 9 6}$} & \multicolumn{2}{c}{$\mathbf{2 0 1 1}$} & \multicolumn{2}{c}{ Change } \\
\cline { 2 - 7 } & Area, $\mathbf{~ k m}^{\mathbf{2}}$ & $\mathbf{\%}$ of total & Area, $\mathbf{~ k m}^{\mathbf{2}}$ & $\mathbf{\%}$ of total & Area, $\mathbf{~ k m}^{\mathbf{2}}$ & \% change (Equation (1)) \\
\hline Agriculture & 83.46 & 44.77 & 84.96 & 48.11 & 1.5 & 0.8 \\
Aquaculture & 61.53 & 33.0 & 41.76 & 23.63 & -19.77 & -32.25 \\
Industry & 8.63 & 4.62 & 20.01 & 11.33 & 11.38 & 131.87 \\
Residential area & 7.08 & 3.79 & 12.18 & 6.90 & 5.10 & 72.03 \\
Sandy coast & 3.87 & 2.08 & 0.29 & 0.16 & -3.58 & -92.51 \\
Vegetation & 1.35 & 0.72 & 1.89 & 1.07 & 0.53 & 39.26 \\
Abandoned land & 0 & - & 0.54 & 0.31 & 0.54 & 0.31 \\
\hline River & 14.79 & 7.93 & 11.51 & 6.52 & - & - \\
Road & - & - & 3.47 & 1.96 & - & - \\
Cloud & 5.72 & 3.06 & - & - & - & - \\
\hline Total area & $\mathbf{1 8 6 . 4 4}$ & - & $\mathbf{1 7 6 . 6 0}$ & - & & \\
\hline
\end{tabular}

\subsection{Shoreline Dynamics}

The total length of Yunlin shoreline in 1996 was $48.02 \mathrm{~km}$, and $49.39 \mathrm{~km}$ in 2011. Protrusion-like reclaimed land areas appeared in 2011 are excluded when mapping and delineating the shoreline. According to the shoreline position map (Figure 3), the Yunlin shoreline has experienced significant changes with both accretion and erosion between 1996 and 2011. However, accretion is more prominent than erosion. The total accreted area is about $2.43 \mathrm{~km}^{2}$ and the total eroded area is about $0.78 \mathrm{~km}^{2}$. The net shoreline change in Yunlin County between 1996 and 2011 is an accretion with $1.65 \mathrm{~km}^{2}$ area.

Figure 3. Shoreline positions in 1996 and 2011.

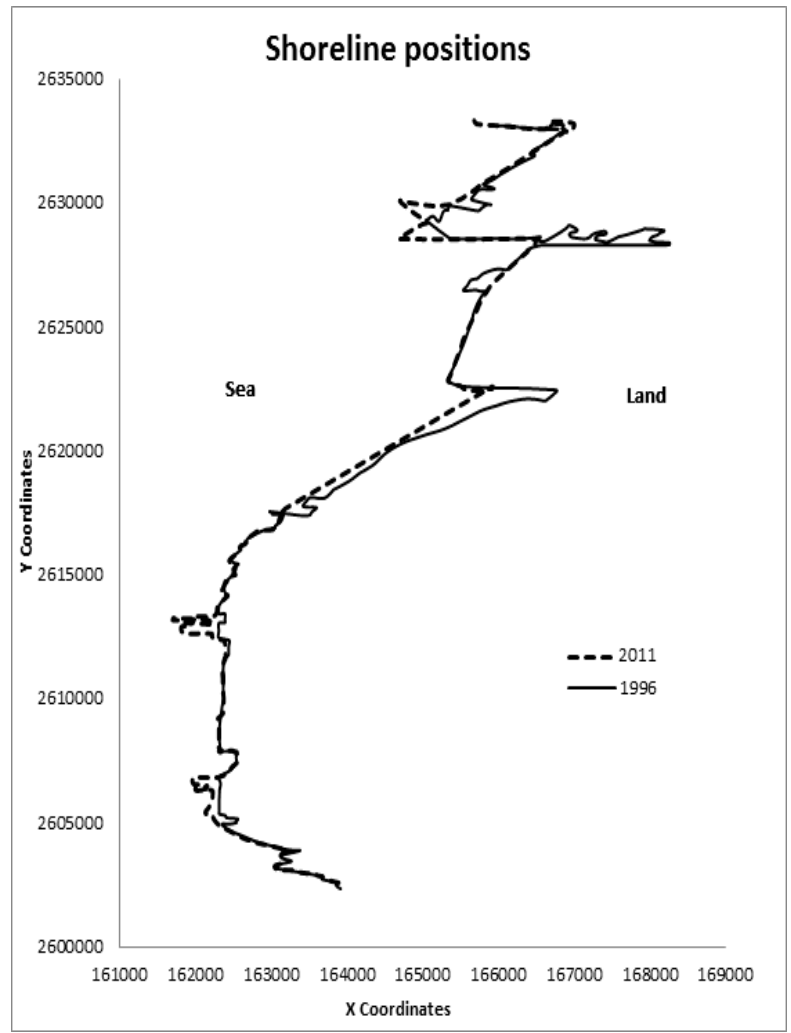




\subsection{Influence of Coastal Land Use Changes on Shoreline Dynamics}

Relationships between land use area change and shoreline area change indicate that segment areas $3 \times 5 \mathrm{~km}^{2}, 4 \times 5 \mathrm{~km}^{2}, 5 \times 5 \mathrm{~km}^{2}$ yield significantly higher correlations values (R) than others (Table 2). This also points to the fact that segment area size less than $3 \times 5 \mathrm{~km}^{2}$ has insignificant effect on the shoreline dynamics.

Table 2. Correlation values $(\mathrm{R})$ between land use area change and shoreline area change for various segment areas.

\begin{tabular}{lccccc}
\hline \multirow{2}{*}{ Land use type } & \multicolumn{5}{c}{ Land segment area $\left.\mathbf{( k m}^{\mathbf{2}}\right)$} \\
\cline { 2 - 6 } & $\mathbf{1} \times \mathbf{5}$ & $\mathbf{2} \times \mathbf{5}$ & $\mathbf{3} \times \mathbf{5}$ & $\mathbf{4} \times \mathbf{5}$ & $\mathbf{5} \times \mathbf{5}$ \\
\hline Agriculture & -0.07576 & -0.16997 & -0.33368 & -0.63442 & -0.03732 \\
Aquaculture & 0.03602 & -0.00581 & 0.13097 & 0.55868 & -0.08122 \\
Industrial & 0.26560 & 0.16190 & 0.22830 & 0.61890 & 0.25119 \\
Residential & -0.10591 & 0.03128 & 0.03753 & -0.34081 & -0.59850 \\
Sandy coast & -0.62833 & -0.62076 & -0.80019 & -0.67038 & -0.89151 \\
Vegetation & -0.02478 & 0.07786 & 0.05778 & -0.20293 & -0.31346 \\
Abandoned & -0.39398 & -0.04636 & -0.07340 & -0.44716 & -0.50965 \\
\hline
\end{tabular}

The correlation values may further infer how changes in each land use type influence shoreline change, in terms of both accretion and erosion. If correlation implies shoreline area decrease, the interpretation is either reduction of accretion or increase of erosion (moving shoreline towards land ward). If correlation implies shoreline increase, the interpretation is increase of accretion or reduction of erosion (shifting shoreline towards sea ward).

\subsubsection{Agriculture Land}

According to Table 2, the segment with area $4 \times 5 \mathrm{~km}^{2}$ gives the highest correlation between agriculture land area change and shoreline area change (-0.63442). Since this is a negative correlation, it implies an increase of agricultural land in study area between 1996 and 2011 has influenced either increase of shoreline erosion area or decline of accretion area. Both of these situations may move shoreline land ward. Therefore, the expansion of agriculture land area in Yunlin coastal zone has a negative impact on the County's shoreline.

In Yunlin County, due to deficiency of water resources, ground water has been abundantly used as an alternative for agricultural purposes [12]. As a result of this, over-exploitation of ground water in the southern coastal regions in Taiwan experience serious and irreversible land subsidence problems. Tung and $\mathrm{Hu}$ [13] identified Yunlin as one of the counties in Taiwan with serious land subsidence problem mainly because of the agricultural needs. Accordingly, with increasing coastal agricultural land, the movement of shoreline is towards land and a negative impact on shoreline. 


\subsubsection{Aquaculture Land}

Aquaculture land area change gives the highest correlation value, 0.558676, for land segment with $4 \times 5 \mathrm{~km}^{2}$ area, indicating a moderate positive correlation between the two variables (Table 2). This correlation implies that aquaculture land area decrease has a negative impact on shoreline. In the southern part of the study area, many aquaculture ponds have been converted into farmland between 1996 and 2011. Therefore, the decline of aquaculture land also exerts indirectly negative impact on the shoreline. Shoreline moves landward either by increasing area of erosion or decreasing accretion area.

\subsubsection{Industrial Land}

The land segment area of $4 \times 5 \mathrm{~km}^{2}$ area gives the highest correlation value (0.61890) (Table 2). Since it is a fairly strong positive correlation, increase of industrial land has a fairly strong influence to move the shoreline seaward either by expanding accreted area or reducing erosion area. In areas occupied with industrial activities in Yunlin, the shoreline depicts a strong accretion pattern, mainly due to land reclamation projects (Figure 4).

Figure 4. Shoreline accretion due to industrialization growth.

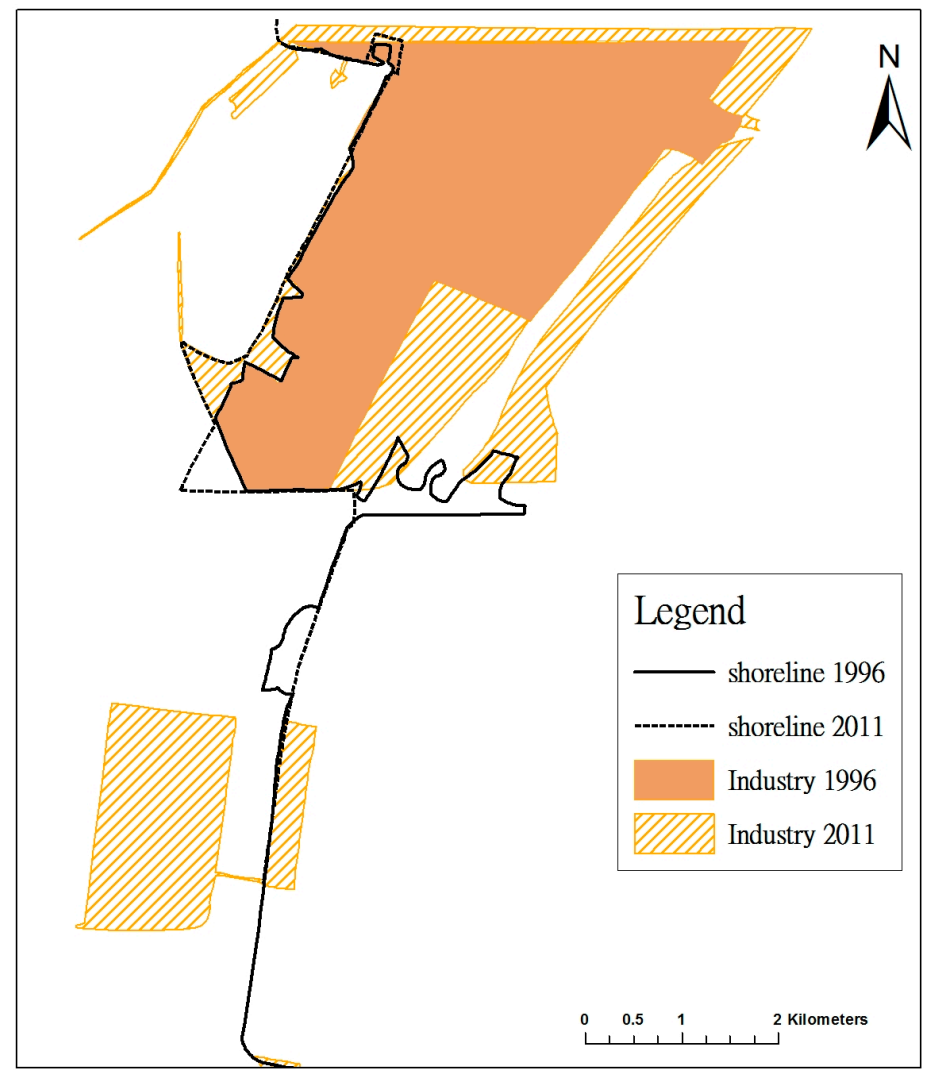

The most significant land use change observed in Yunlin coastal zone between 1996 and 2011 is the dramatic increase of industrial area along the shoreline. The main industrial estate in the study area, Yunlin Offshore Industrial Estate covers the entire shoreline in the northern part of the study site. This estate starts construction in 1994 [14]. Thus, only a small area is occupied by industrial activities in the 1996 image and consists mainly with several reclamation sites. Since these activities are located along 
the shoreline, they have replaced almost all the sandy coasts present in the study area. Sandy coasts are rarely found along the Yunlin shoreline nowadays and limited to very small areas. The Yunlin shoreline in 2011 consisted mainly of man-made landscapes. In addition, the shoreline adjacent to the industrial activities shows a significant accretion pattern due mainly to land reclamation and loss of sandy coast.

\subsubsection{Residential Land}

According to Table 2, the highest correlation value observed for residential land area change and shoreline area change is -0.59850 with land segment area of $5 \times 5 \mathrm{~km}^{2}$. This fairly strong negative correlation indicates an inverse relationship between residential land area change and shoreline area change. Increase of residential area has a negative influence on shoreline stabilization. In other words, it increases shoreline erosion area or reduces accreted area, shifting shoreline position towards land, creating a negative impact on shoreline position.

Expansion of residential area and urbanization often bring harmful impacts on the coastal zone and cause negative influence on the shoreline due to coastal erosion or natural accretion reduction. As Sekhar [15] explained, human population increase in coastal areas would result in over-exploitation of natural sources in coastal zones and serious degradation of coastal ecosystems. Since Yunlin County already experiences ground water over-exploitation, residential growth directly worsens this situation resulting in more land subsidence and coastal erosion. Urban growth can induce coastal erosion in many other ways as well, including reduction of sediment supply to the coast, conversion of sandy coast into residential area as well as destruction of mangrove ecosystems which act as a barrier to coastal erosion. In Yunlin coastal area, human settlements are concentrated close to rivers. As a result, the amount of sediment delivered by rivers to the coasts may be reduced and results in negative impact to the position of the shoreline.

\subsubsection{Sandy Coast Land}

The highest correlation $(-0.89151)$ obtained for the sandy coast area change and shoreline area change is with land segment area of $5 \times 5 \mathrm{~km}^{2}$ (Table 2). This strong negative correlation value indicates a significant strong influence of sandy coast area change on shoreline dynamics between 1996 and 2011. This also is the highest correlation obtained for all land use types, indicating the change of sandy coast area has the most significant influence on shoreline dynamics in Yunlin County. Decrease sandy coast area usually has significantly negative influence, moving shoreline towards land by enhancing shoreline erosion or by reducing accretion. However, according to observations of the present study, the shoreline next to the sandy coast often experience significant accretion patterns due to land reclamation activities disturbing natural sandy coast, resulting in a positive impact to the Yunlin shoreline position (Figure 5).

\subsubsection{Vegetation Land}

Vegetation area change gives insignificantly small correlation values with shoreline area change. The highest value, -0.31346 , is obtained with land segment area of $5 \times 5 \mathrm{~km}^{2}$ (Table 2). This is a 
negative correlation which describes an inverse relationship between vegetation area change and shoreline change. Increasing vegetation area influences shoreline movement towards land either by enhancing shoreline erosion area or lowering accretion, causing negative impact to the shoreline.

The cause of this effect is the same as with the agricultural land. Results of groundwater extraction lead to land subsidence and further enhance negative impact on the shoreline.

Figure 5. Between 1996 and 2011 sandy coasts have decreased due to industrial activities and the shoreline has moved towards the sea.

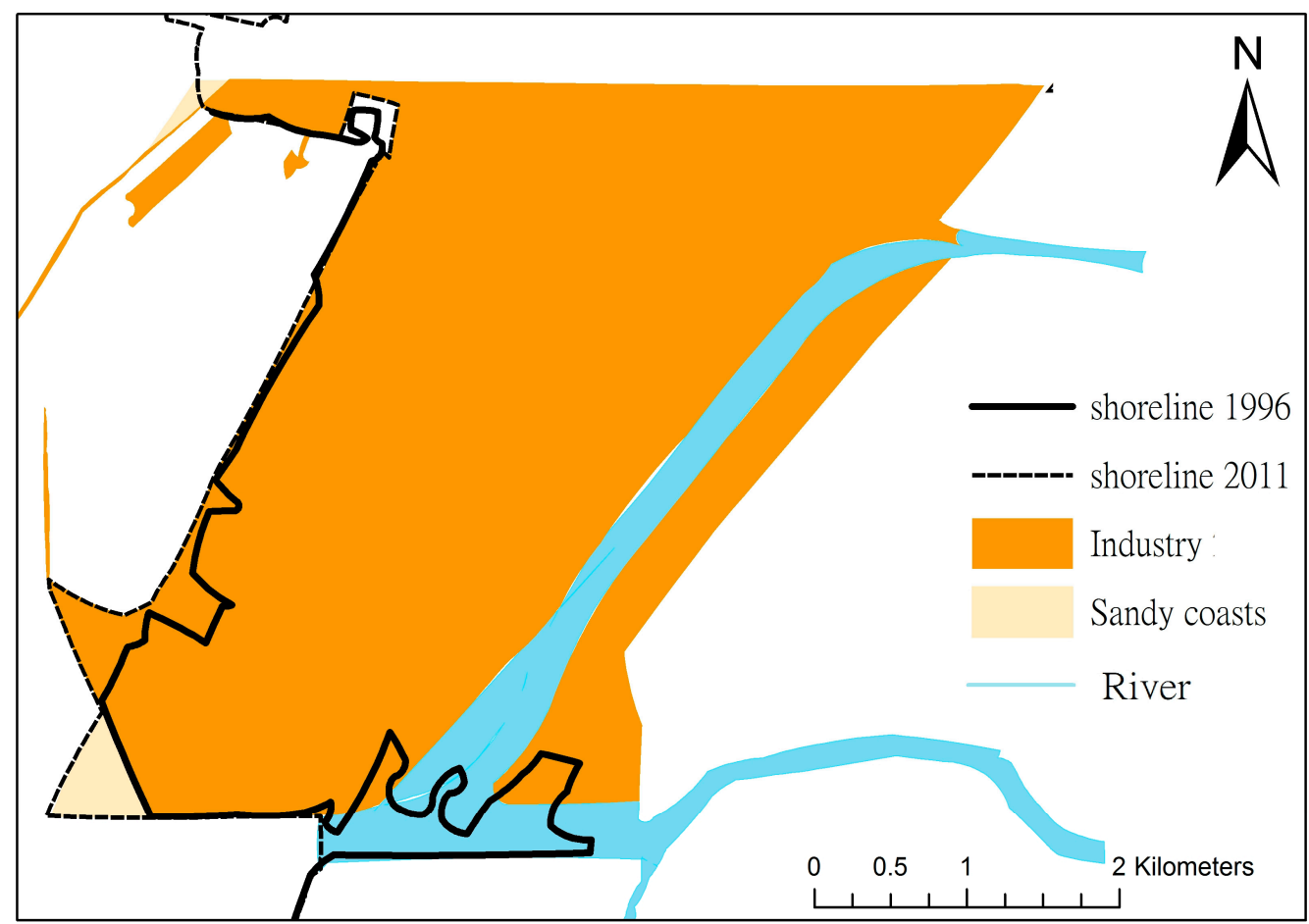

\subsubsection{Abandoned Land}

Abandoned land areas are extremely small. Area change yields negative correlation with shoreline area change for all segment areas (Table 2). The highest value is associated with land segment area of $5 \times 5 \mathrm{~km}^{2}$, indicating that this area size is more appropriate to analyze the correlation between abandoned land area change and shoreline dynamics. The highest correlation value is about -0.50965 , a moderately strong negative correlation. The increase of abandoned land may enhance shoreline erosion and a negative impact on shoreline, moving its position more towards land.

\section{Conclusions}

Land use changes in the Yunlin coastal area between 1996 and 2011 has created both positive and negative impacts on the shoreline. The negative impact brought by agriculture area change has been reported by many other studies. Factors affecting shoreline erosion include: reduction of sediment transportation to the coast, land subsidence, and destruction of the natural coastal environment.

Increase of industrial land and loss of sandy coast have a positive impact on the Yunlin shoreline. This influence is mainly due to accretion caused by land reclamation projects. The correlation between 
sandy coast area change and shoreline area change is the highest among all land use types, indicating the change of sandy coast area is the most significant influence on shoreline dynamics in Yunlin County. Industrial and sandy coast area change has a positive impact on the shoreline as a result of accretion due to man-made constructions. However, it has created several adverse consequences for the marine life living near shallow water in Yunlin County as well as the coastal natural landscape. According to Wang et al. [16], land reclamation projects in the west coast of Taiwan is one of the major threats to the Taiwan Pink Dolphin (Sousa chinensis), inhabiting the near shallow water along the west coast of Taiwan, and listed with "critically endangered" conservation status due to its extremely small population size.

Results of this study clearly illustrate how human induced land use changes can influence shoreline stability and especially how industrialization can change the natural environment of coastal areas and their negative consequences. Even though accretion occurred in Yunlin coastal areas between 1996 and 2011, due mainly to man-made land reclamation activities, it may cause several adverse impacts to the coastal environment. Findings of this study are helpful in future coastal management activities, and to maintain a balanced and sustainable coastal zone in Yunlin County.

\section{Author Contributions}

Kwong Fai A. Lo had the original idea for the study, supervised the research work and was responsible for revising the manuscript. Chethika W. D. Gunasiri was responsible for data collection, carried out the analyses and drafted the first version of the manuscript. Both authors read and approved the final manuscript.

\section{Conflicts of Interest}

The authors declare no conflict of interest.

\section{References}

1. Addo, K.A.; Jayson-Quashigah, P.N.; Kufogbe, K.S. Quantitative analysis of shoreline change using medium resolution satellite imagery in Keta, Ghana. J. Mar. Sci. 2011, 1, 1-9.

2. Cai, F.; Liu, J.; Bing, L.; Gang. L. Coastal erosion in China under the condition of global climate change and measures for its prevention. Progr. J. Nat. Sci. 2009, 19, 415-426.

3. Klein, M.; Lichter, M. Monitoring changes in shoreline position adjacent to the Hadera power station, Israel. J. Appl. Geogr. 2006, 26, 210-226.

4. Griffiths, C.J. The impact of Sand Extraction from Seasonal Streams on Erosion of Kunduchi Beach. In Beach Erosion along Kunduchi Beach, North of Dar es Salaam; A Report for NEMC by Beach Erosion Monitoring Committee; Kunduchi, Tanzania, 1988; p. 55. 
5. Mimura, N. Conclusions: The Rapidly Changing Environment of the Asia and Pacific Region and its Implications for Sustainability of the Coastal Zones. Asia-Pacific Coasts and Their Management. Available online: http://books.google.com.tw/books?id=dgXnSZ300NAC\&printsec $=$ frontcover \&dq $=$ Mimura,$+2008+$ Conclusions: + The + Rapidly + Changing + Environment + of + the $+A$ sia + and + Pacific + Region + and + its + Implications + for + Sustainability + of + the + Coastal + Zones + AsiaPacific + Coasts + and + Their + Management\&hl=en\&sa=X\&ei=8pI1UqyfGoLHkgWRpICQAg\&ve (accessed on 13 October 2013).

6. Rio, L.D.; Gracia, F.J.; Benaventae, J. Shoreline change patterns in sandy coasts. A case study in SW Spain. J. Geomorphol. 2013, 196, 252-266.

7. Ahmed, A. Some of the major environmental problems relating to land use changes in the coastal areas of Bangladesh. J. Geogr. Reg. Plan. 2011, 4, 1-8.

8. Ericson, J.P.; Vörösmarty, C.J.; Dingman, S.L.; Ward, L.G.; Meybeck, M. Effective sea-level rise and deltas: Causes of change and human dimension implications. J. Glob. Planet. Change 2006, $50,63-82$.

9. Chang, C.; Lee, H.; Lin, Y.C.; Chien, L.K. Disaster Risk Analysis of Coastal Zones in Taiwan in Responses to Sea Level Rise; Cities at Risk: Building Adaptive Capacities for Managing Climate Risks in Asian Coastal Cities (CAR II); The Academy of Sciences located in Taipei: Taipei, Taiwan, 2011; p. 68.

10. Lin, J.C. Coastal modification due to human influence in south-western Taiwan. J. Quat. Sci. Rev. 1996, 15, 895-900.

11. Hsu, W.C.; Chang, K.C.; Cheng, J.; Liu, J.K. Land use and land cover change in association with land subsidence in Yunlin area, Middle Taiwan. In Proceedings of International Conference on Earth Observations and Societal Impacts, Taipei, Taiwan, 25-27 June 2012.

12. Liu, C.; Shih, T.A.; Su, J.C. Coastal morphological evolution investigation on Yunlin offshore industrial estate. In Proceedings of the Twelfth International Offshore and Polar Engineering Conference, Kitakyushu, Japan, 26-31 May 2002.

13. Hsu, S.K.; Hsu, H.T.; Tsai, M.C. Implementation of land subsidence and reclamation plans in Taiwan. In Proceedings of the 10th Afro-Asian Regional Conference-Water and Land Resources Development and Management for Sustainable Use II-A, Denpasar-Bali, Indonesia, 19-24 July 1998.

14. Tung, H.; Hu, J.C. Assessments of serious anthropogenic land subsidence in Yunlin County of central Taiwan from 1996 to 1999 by persistent scatterers in SAR. J. Tectonophys. 2012, 578, 126-135.

15. Sekhar, N.U. Integrated coastal zone management in Vietnam: Present potentials and future challenges. J. Ocean Coast. Manage. 2005, 48, 813-827. 
16. Wang, J.Y.; Yang, S.C.; Reeves, R.R. Report of the First Workshop on Conservation and Research Needs of Indo-Pacific Humpback Dolphins, Sousa chinensis, in the Waters of Taiwan; The National Museum of Marine Biology and Aquarium: Checheng, Pingtung County, Taiwan, 2004; p. 6.

(C) 2014 by the authors; licensee MDPI, Basel, Switzerland. This article is an open access article distributed under the terms and conditions of the Creative Commons Attribution license (http://creativecommons.org/licenses/by/4.0/). 